\title{
Sciatica secondary to sciatic nerve schwannoma
}

\author{
M. F. Hamdi, I. Aloui, Kh Ennouri
}

Department of Trauma and Orthopedic surgery, F. Bourguiba University Hospital, 5000 Monastir, Tunisia

A 45-year-old man attended neurosurgery department for right lower limb burning pain of three months duration. The pain was intermittent, exacerbated by sitting position, and radiated from the proximal posterior part of the right lower limb to the lateral area of the leg, and the dorsal aspect of the foot. The pain was not severe enough to disturb sleep, or to hinder physical activities. The deep palpation of the posterior part of the right thigh revealed a soft tissue mass, and reproduced the same pain. Tinel sign was absent. Magnetic resonance imaging (MRI) showed a mass involving the right sciatic nerve in its proximal portion [Figure 1a and b]. The right sciatic nerve was exposed through a posterior approach. At operation the tumor was surrounded by a capsule (the epineurium) which allowed complete enucleation without damage to the

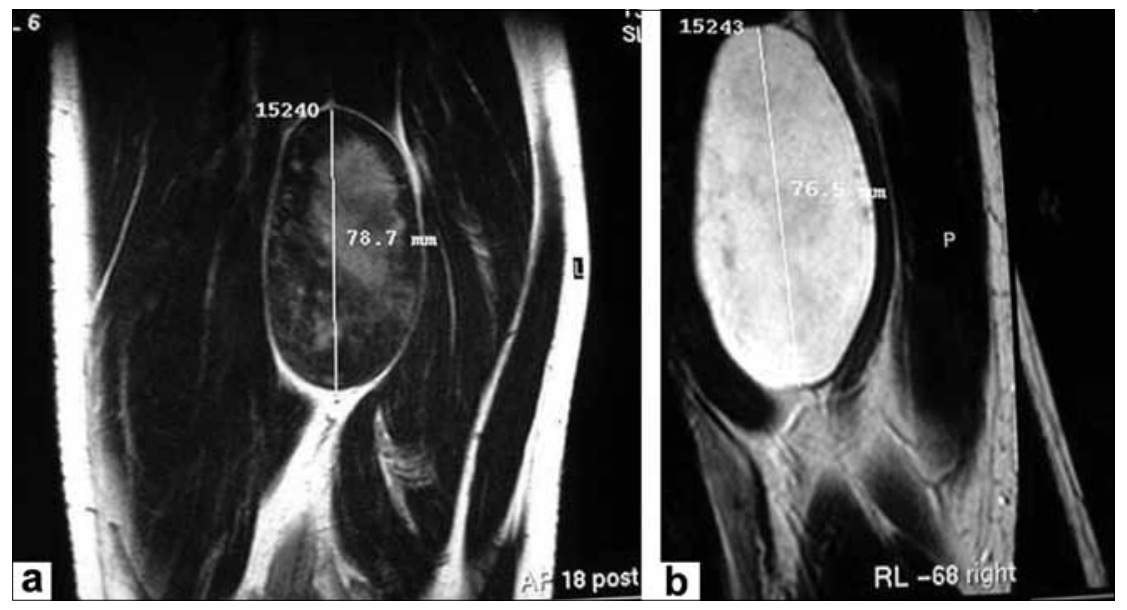

Figure 1: (a) T1 weighted axial right thigh magnetic resonance imaging showing schwannoma; the signal intensity of tumour is similar to that of muscles; (b) Schwannoma with high signal intensity in T2 weighted axial right thigh Magnetic resonance imaging
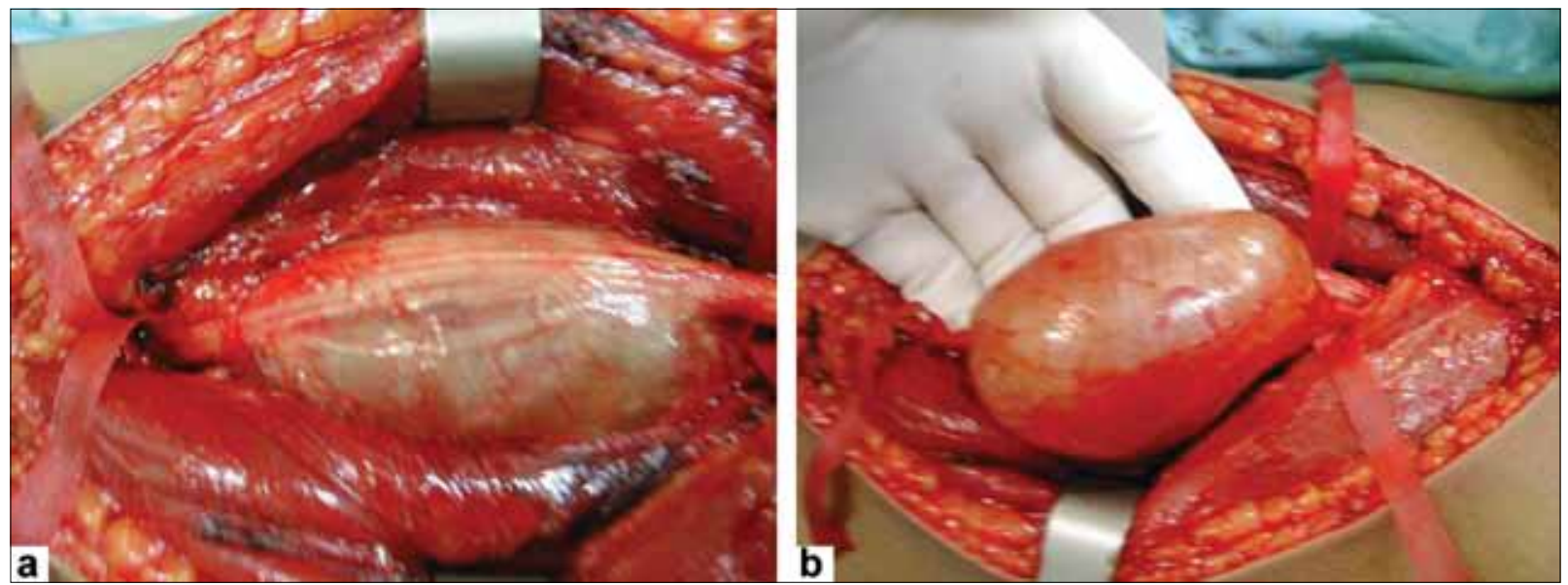

Figure 2: (a) Operative view, the schwannoma placed eccentrically in the sciatic nerve; (b) Operative view, the schwannoma was easily enucleated without damage of the sciatic nerve 
fascicular structure of the sciatic nerve [Figure 2a and b]. Histological examination confirmed the diagnosis of schwannoma. Postoperatively the patient has complete relief from pain and there was no neurologic deficit.

Schwannoma of sciatic nerve is uncommon and the reported frequency was less than $1 \% .{ }^{[1]}$ Sciatic nerve schwannoma may be asymptomatic or may be associated with pain or paresthesias in the distribution of the nerve. Mortor and sensory deficits are more common with large size $(4 \mathrm{~cm})$ tumors ${ }^{[1-3]}$ Magnetic resonance imaging provides an excellent quality views of the schwannoma necessary for surgical strategy. On T1-weighted images, schwannoma has intermediate signal intensity similar to that of muscles, and on T2-weighted, the tumor shows high signal. The schwannoma enhances uniformly after gadolinium. ${ }^{[2]}$ Heterogeneous enhancement is seen in cystic or necrotic forms of schwannoma. Surgical outcome in sciatic nerve shwannoma is good. ${ }^{[1]}$ Sciatic nerve schwannoma though rare should be included in the differential diagnosis of sciatica.

$$
\begin{array}{r}
\text { Address for correspondence: } \\
\text { Dr. Hamdi Mohamed Faouzi (MF), } \\
\text { Department of Trauma and Orthopedic Surgery, } \\
\text { F. Bourguiba University Hospital } 5000 \text { Monastir, Tunisia. } \\
\text { E-mail: hamdi.medfaouzi@yahoo.fr } \\
\text { PMID: } 19934583 \\
\text { DOI: 10.4103/0028-3886.57786 }
\end{array}
$$

\section{References}

1. Wolock BS, Baugher WH, McCarthy EJ. Neurilemoma of the sciatic nerve mimicking tarsal tunnel syndrome. Report of a case. J Bone Joint Surg Am 1989;71:932-4.

2. Pilavaki M, Chourmouzi D, Kiziridou A, Skordalaki A, Zarampoukas T, Drevelengas A. Imaging of peripheral nerve sheath tumors with pathologic correlation: Pictorial review. Eur J Radiol 2004;52:229-39.

3. Sawada T, Sano M, Ogihara H, Omura T, Miura K, Nagano A. The relationship between pre-operative symptoms, operative findings and postoperative complications in schwannomas. J Hand Surg Br 2006;31:629-34.

Accepted on 02-07-2009

Source of Support: Nil, Conflict of Interest: None declared. 